National Perinatal Epidemiology Unit, Nuffield Department of Population Health, University of Oxford, Oxford, UK

2 Institute of Applied Health Research, University of Birmingham, Birmingham, UK

3 UK Obstetric Surveillance System Steering Committee, National Perinatal Epidemiology Unit, Oxford, UK

4 School of Life Course Sciences, King's College London, London, London, UK

Correspondence to: LC Chappell lucy.chappell@kcl.ac.uk

Cite this as: BMJ 2020;370:m3305 http://dx.doi.org/10.1136/bmj.m3305 Published: 25 August 2020

\title{
Include pregnant women in research-particularly covid-19 research
}

\author{
Adapting interventions and changing attitudes will drive scientific progress \\ Marian Knight, ${ }^{1}$ R Katie Morris, ${ }^{2}$ Jenny Furniss, ${ }^{3}$ Lucy C Chappell ${ }^{4}$
}

The UK Confidential Enquiries into Maternal Deaths have repeatedly highlighted inequities in the medical treatment of pregnant and postpartum women, noting that women are denied investigations and life preserving treatments simply because they are pregnant or breastfeeding. ${ }^{12}$ These inquiries emphasise that the default position should be to investigate and treat pregnant and breastfeeding women in the same way as non-pregnant women, unless there are clear reasons not to. ${ }^{1}$

Clinical trials, particularly those of drug treatments, have typically automatically excluded pregnant or breastfeeding women, meaning data are unavailable on safety and effectiveness. These challenges were noted by the Task Force on Research Specific to Pregnant Women and Lactating Women, ${ }^{3}$ which issued 15 recommendations, centred around tackling the cultural assumptions that limit scientific progress into preventive and therapeutic interventions for pregnant women.

This disparity in trial inclusion has been exacerbated in the covid-19 pandemic. A recent review reported that of 927 trials related to covid-19, 52\% explicitly excluded pregnancy, $46 \%$ did not mention pregnancy, and only $1.7 \%$ specifically included pregnancy, of which just three were interventional trials. ${ }^{4}$ The risks of untested interventions have been highlighted by others, ${ }^{5}$ and the moral imperative to include pregnant women in such trials is obvious, ${ }^{6}$ but the mechanisms to do so are less clear.

\section{Dealing with safety concerns}

The RECOVERY (Randomised Evaluation of Covid-19 Therapy) trial shows that excluding pregnant and breastfeeding women need not be the default option. ${ }^{7}$ Inclusion of these women in trials has challenges, and approaches developed for the RECOVERY trial provide a template for other studies.

Concern over safety of drugs or other interventions for the developing fetus drives the presumption that pregnant women should be excluded from clinical trials. However, information on safety is often available for repurposed drugs that are already in routine use for pregnancy specific indications or other long term conditions. For example, in the RECOVERY trial, data already existed on the use of

lopinavir-ritonavir to treat HIV and

hydroxychloroquine for lupus during pregnancy. The researchers also recognised the need to adapt interventions; dexamethasone was substituted with prednisolone or hydrocortisone (which have low placental transfer) to avoid the adverse fetal effects reported with multiple courses of dexamethasone. ${ }^{8}$ Infrastructure within regulatory authorities to provide review by experts in using interventions in pregnancy or breastfeeding allows safety concerns to be allayed for women, their families, and healthcare professionals.

Even if regulatory barriers have been overcome, gatekeeping or inertia may occur if local ethics committees take an overwhelming precautionary approach, overriding recognition of the potential benefits of including pregnant and breastfeeding women. This problem can be mitigated by a strong network of maternity researchers, familiar with delivering drug trials in pregnancy, who can be rapidly mobilised to help implement studies.

The pressure on health services in the pandemic necessitates streamlined approaches to clinical trials. The need to add data collection about pregnancy and infant outcomes is perceived as a disincentive to the inclusion of pregnant women. However, linkage to routinely collected information can easily capture basic follow-up data. If these data do not have sufficient clinical nuance to address key research questions-such as decisions around timing of iatrogenic birth-additional linkage to other research data may provide a solution. The UK Obstetric Surveillance System, ${ }^{9}$ part of an international network, ${ }^{10}$ facilitated rapid roll-out of national observational studies of covid-19 in pregnancy, designed before the pandemic in readiness, ${ }^{11}$ and includes these extended data.

\section{Changing the default}

These examples show how some of the barriers caused by regulatory and other trial processes can be overcome to include pregnant and breastfeeding women even within a rapidly evolving pandemic. As increasing numbers of women are entering pregnancy with pre-existing conditions and may potentially benefit from newer therapies, now is the time to default to including, rather than excluding, pregnant and breastfeeding women in general clinical trials. ${ }^{12}$ The RECOVERY trial is an example of success in equity for pregnant women, but the number of included women remains small and planned international meta-analyses of trial subgroup data on pregnant women will be essential.

These approaches alone will not make a difference without a change in attitudes among all of us. The covid-19 pandemic has led many of us to move out of our clinical "comfort zone." We must also move out of our research comfort zone, developing rapid new international multidisciplinary collaborations and being open to a wider trial scope. International change may require reconsideration of legal frameworks, including those governing the rights of both mothers and unborn children. 
Pregnant women are currently excluded from all covid-19 vaccine trials, ${ }^{13}$ and we may face the paradoxical situation of recommending vaccination for a risk group in which the vaccine is untested.

Ensuring equity of trial inclusion and subsequent meta-analysis so that pregnant women can benefit fully from potentially lifesaving treatments is thus even more urgent.

Competing interests: The authors have read and understood BMJ policy on declaration of interests and declare that we have no competing interests.

Provenance and peer review: Not commissioned; externally peer reviewed.

We thank Richard Haynes for his comments on the manuscript.

1 Knight M, Bunch K, Tuffnell D, etal, eds. Saving lives, improving mothers' care-lessons learned to inform maternity care from the UK and Ireland Confidential Enquiries into Maternal Deaths and Morbidity 2015-17. National Perinatal Epidemiology Unit, University of Oxford,2019.

2 Knight M, Bunch K, Tuffnell D, etal. Saving lives, improving mothers' care-lessons learned to inform maternity care from the UK and Ireland Confidential Enquiries into Maternal Deaths and Morbidity 2014-16. National Perinatal Epidemiology Unit, University of Oxford,2018.

3 Byrne JJ, Saucedo AM, Spong CY. Task force on research specific to pregnant and lactating women. Semin Perinatol 2020;44.. doi: 10.1016/.j.semperi.2020.151226 pmid: 32173086

4 Smith DD, Pippen JL, Adesomo AA, Rood KM, Landon MB, Costantine MM. Exclusion of pregnant women from clinical trials during the coronavirus disease 2019 pandemic: a review of international registries. Am J Perinatol 2020;37:792-9. doi: 10.1055/s-0040-1712103 pmid: 32428965

5 Browne J, van der Zande I, van Smeden M, van der Graaf R. Protect pregnant women by including them in clinical research. BMJ 2018;362:k4013. doi: 10.1136/bmj.k4013 pmid: 30257821

6 Malhamé I, D'Souza R, Cheng MP. The moral imperative to include pregnant women in clinical trials of interventions for COVID-19. Ann Intern Med 2020; [Epub ahead of print]. doi: 10.7326/M20-3106 pmid: 32598164

7 Horby P, Lim W, Emberson J, et al. Effect of dexamethasone in hospitalized patients with COVID-19: preliminary report. medrxiv 2020.06.22.20137273v1 [Preprint.] https://www.medrxiv.org/content/10.1101/2020.06.22.20137273v1

8 Newnham JP, Simmer K. Multiple courses of antenatal corticosteroids. Lancet2008;372:2094-5. doi: 10.1016/S0140-6736(08)61903-0 pmid: 19101367

9 Knight M, Lindquist A. The UK obstetric surveillance system: impact on patient safety. Best Pract Res Clin Obstet Gynaecol2013;27:621-30. doi: 10.1016/j.bpobgyn.2013.03.002 pmid: 23548471

10 Knight M. INOSS. The International Network of Obstetric Survey Systems (INOSS): benefits of multi-country studies of severe and uncommon maternal morbidities. Acta Obstet Gynecol Scand 2014;93:127-31. doi: 10.1111/aogs.12316 pmid: 24382256

11 Knight M, Bunch K, Vousden N, etalUK Obstetric Surveillance System SARS-CoV-2 Infection in Pregnancy Collaborative Group. Characteristics and outcomes of pregnant women admitted to hospital with confirmed SARS-CoV-2 infection in UK: national population based cohort study. BMJ 2020;369:m2107. doi: 10.1136/bmi.m2107 pmid: 32513659

12 Chappell LC, David AL. Improving the pipeline for developing and testing pharmacological treatments in pregnancy. PLoS Med 2016;13:. doi: 10.1371/journal.pmed.1002161 pmid: 27802279

13 Farrell R, Michie M, Pope R. Pregnant women in trials of COVID-19: a critical time to consider ethical frameworks of inclusion in clinical trials. Ethics Hum Res 2020;42:17-23. doi: 10.1002/eahr.500060 pmid: 32562594

This article is made freely available for use in accordance with BMJ's website terms and conditions for the duration of the covid-19 pandemic or until otherwise determined by BMI. You may use, download and print the article for any lawful, non-commercial purpose (including text and data mining) provided that all copyright notices and trade marks are retained. 